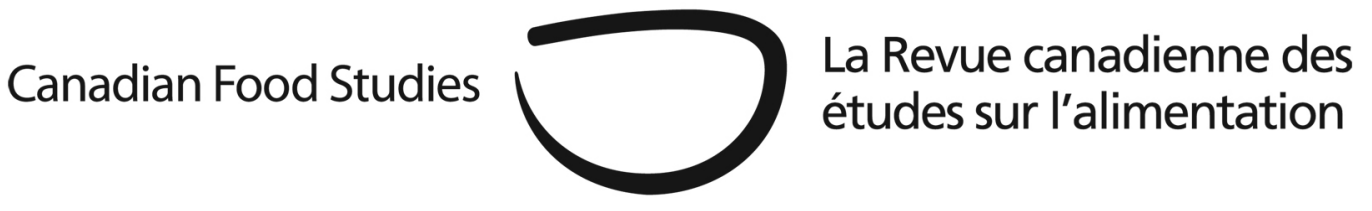

Original Research Article

\title{
GMO doublespeak: An analysis of power and discourse in Canadian debates over agricultural biotechnology
}

\author{
Wesley Tourangeau* \\ School of Environment, Resources and Sustainability, University of Waterloo
}

\begin{abstract}
It has been over 20 years since Canada's first commercially grown genetically modified (GM) crops were approved, and debates over these contentious products continue to gain momentum. Literature exploring Canada's GMO debates has yet to focus specifically on the discourse of probiotech public relations campaigns and anti-biotech movements. This paper helps fill this gap with an analysis of power relations regarding efforts to inform public opinion on the topic of agricultural biotechnology. I explore these power relations in two arguments. First, I argue that the Canadian state's overall positive position toward agricultural biotechnology provides leverage to pro-biotech public relations, while delimiting the direction of anti-biotech campaigns. Second, I argue that the potency of pro-biotech frames are constituted and sustained by historically and culturally embedded norms and values, which add additional challenges for antibiotech campaigns. These findings reveal a clearer picture of the complexity of power relations within agri-biotech discourse, and the extent to which anti-biotech groups may be disadvantaged in these debates.
\end{abstract}

Keywords: agricultural biotechnology; GMO; power; discourse; Canada

*Corresponding author: wtourangeau@uwaterloo.ca 


\section{Introduction}

More than two decades since the first commercial approvals, agricultural biotechnology remains in a state of serious contention both in Canada and around the world. Controversy continues to rage over the potential issues posed by genetically modified (GM) ${ }^{1}$ foods and crops, including impacts to human and animal health, the environment, and the agri-food market (Kondoh \& Jussaume, 2006). Policy development as well as consumer and market acceptance are impacted by the known and/or perceived risks and benefits of agricultural biotechnology. As public policy for GMOs has developed, so too have the ways in which GMOs are framed and discussed. This also means GM technology is susceptible to forms of "doublespeak", or language use that obscures, alters, or re-creates the meanings and understandings of GMOs and their impacts. In an effort to explore connections between these discourses and wider power relations regarding the development and influence of GMO policy, this paper examines the language use within probiotech public relations discourses and anti-biotech campaign discourses.

On the one hand, organizations such as the Council for Biotechnology Information $(\mathrm{CBI})^{2}$, which represents companies including Monsanto and Bayer CropScience (CBI, 2011f), use various campaign strategies to inform the public about the importance and benefits of biotechnology. On the other hand, organizations such as the Canadian Biotechnology Action Network (CBAN) ${ }^{3}$ oppose these efforts, pointing to the risks of genetically modified organisms (GMOs) and questioning the claims of agri-biotech supporters. Though clear power differentials exist between these organizations and their available resources, important insights can also be gleaned through an analysis of materials (such as advertisements, brochures, and factsheets) from both sides of the debate that represent the sorts of messages Canadians receive regarding GM foods and crops. Analysis of these documents reveals how complex power relations impact the production, dissemination, and reception of GMO discourse.

Anti-biotech campaigns have been successful in Canada on numerous occasions, but these victories appear to be localized "wins” within the relatively unchanged Canadian GMO policy climate. While several GM products have been successfully blocked from entering Canada's market, likely by the assistance of CBAN and likeminded groups, there remains a strong pro-GM industry and regulatory system in the country. What factors might explain the definite, but overall limited, success of anti-biotech efforts? This article operationalizes a

\footnotetext{
${ }^{1}$ GM ("genetically modified”) and GMO ("genetically modified organism”) are the preferred terms used in this article to refer to plants that are also referred to as genetically engineered (GE), transgenic, and living modified organisms (LMO). All of which can be considered methods of agricultural biotechnology. GM crops are identified as developed through breeding processes that do not naturally occur. See CFIA (2007) for a more detailed explanation of these terms.

${ }^{2}$ The Council for Biotechnology Information is a "NAFTA-aligned, non-profit association" with individual websites for biotech information regarding the United States, Canada and Mexico (CBI, 2011g). Only the Canadian (English) site is examined here in depth.

${ }^{3}$ CBAN is a network made up of 16 members, who include: Canadian Organic Growers, GE Free Yukon, No More GMOs Toronto, and the Saskatchewan Organic Directorate.
} 
multiform approach to power in order to explore the language, contexts, and social relations influencing debates over GMOs vis-à-vis campaign and publicity materials. The purpose is to expose under-acknowledged conditions and characteristics within GMO debates to help explain the embedded power structures supporting pro-biotech discourses, and the ways in which this discursive climate influences the overall successes and limitations of anti-biotech campaigns. These campaigns represent an important voice pushing back against the current power structure within the Canadian agri-biotech sector, providing key challenges to the current emphases on technological competitiveness and economic growth.

Discourse analysis of 42 key informational documents (campaign reports, flyers, etc.) reveals two key findings regarding power relations (both overt and underlying) in Canada's agribiotech sector. First, the Canadian state's overall positive position toward agricultural biotechnology is influential in providing discursive leverage to pro-biotech publicity materials, while predisposing and delimiting the directions of many anti-biotech campaign materials. Second, pro-biotech frames are attached to popular values and constructed within historical, cultural, and normative understandings of "truth" production, which increases their resonance; while anti-biotech campaign materials appear more stymied by these conditions. Overall, these findings help to illustrate the complexity of power relations within agri-biotech discourse, and the extent to which anti-biotech groups are disadvantaged in these debates. Importantly, the concepts of technological progressivism and scientism are used in this study to highlight the sort of normative assumptions that enable the framing of certain problems as solvable through agricultural biotechnology. Technological progressivism (or technological determinism), is the view that technological development is not only beneficial, but inevitable; such ideas can be dated back to the Enlightenment and the de-legitimation of the Luddites in the 19th century (Kleinman \& Kinchy, 2003; Kleinman \& Kloppenburg, 1991, p. 432). Scientism is the idea that facts, being superior and more credible, must be kept distinct from values-a distinction that has roots as far back as Plato and the creation of science as a profession (Kleinman \& Kinchy, 2003). These two terms are employed in an effort to extend the discussion of power relations beyond the agency of actors in order to expose what relations, norms, histories and ideas enable/disable this agency. This analysis is meant to fill a gap in Canadian research on GMO media and discourse analysis, as well as contribute to wider discussions regarding power and biotechnology.

\section{Power and language in GMO debates}

Throughout the last two decades an array of debates over agricultural biotechnology has consistently appeared within social and political domains. Much of the discourses surrounding GM foods and crops remain embedded in binary divisions such as safe/not-safe, sustainable/unsustainable, necessary/unnecessary, and so forth. For instance, a key debate over the value and necessity of agricultural biotechnology is over its capacity to feed a growing population. One view states that GMOs are necessary to feed eight billion people in 2025 
(Borlaug, 2004); the opposing view is that this claim is mostly rhetoric designed to both maintain the illusion that GMOs are needed, and to mask the overall failures in addressing global hunger with these technologies (Chopra, 2015). Such socio-political divisions are interlaced with scientific debates, which often become more divisive through the translation and communication of scientific research in varying mediums (for instance pro-biotech public relations materials and anti-biotech campaign materials).

Research on GMO safety has focused on either demonstrating that GM foods and crops are as safe as conventionally made foods and crops, or establishing the need for additional research due to remaining uncertainty and complexity. Scientific research, particularly since 2006, has examined the safety of genetically modified foods, including issues of toxicity, adverse effects, and health risks, and according to Domingo and Bordonaba (2011) displays "a certain equilibrium in the number of research groups suggesting, on the basis of their studies, that a number of varieties of GM products (mainly maize and soybeans) are as safe and nutritious as the respective conventional non-GM plant, and those raising still serious concerns” (p. 741). More recently, Hilbeck et al. (2015) contributed to the discussion by claiming that no scientific consensus on GMO safety has been reached - a publication that includes notable GMO critics in the list of authors, such as Vandana Shiva and Brian Wynne. Adding to this debate, the United States' National Academies of Sciences, Engineering, and Medicine (2016) recently released an extensive report titled “Genetically Engineered Crops: Experiences and Prospects”, which includes statements claiming the lack of proof that GM foods are less safe than other foods made from non-GM ingredients. Each side of this scientific division is emphasized and mobilized in an effort to win public approval. For example, large-scale corporations and supportive governments mobilize particular discourses that depict GMOs as beneficial and safe, consistently pointing to a lack of scientific proof that GMOs are dangerous, and emphasizing the similarities of genetic modification with conventional plant breeding. Conversely, anti-biotech groups often emphasize the opposite, pointing to the remaining uncertainty regarding GMO safety, and the unique risks they pose. As these debates continue in scientific, political, and social domains, there remains a need to better understand the impacts of GMO discourse and the associated relations of power.

\section{GMO doublespeak and historical resonance}

Power and language in GMO debates is an important area of research, helping to reveal the role of discourse in battles over public opinion. In this article, the discursive domain of GMOs is explored to illustrate the influence of normatively and historically embedded discourses, and the power effects that may undulate from their deployment. Though there are plenty of examples of "GMO doublespeak" - the strategic political framing of GM products and their impactsimportant insights are also found in an exploration of the histories, norms, and ideas in which these frames are embedded.

An important example of framing in GMO debates is in the area of intellectual property (IP). While opponents of GM technologies point to concerns regarding increased corporate 
control over seeds and related issues, proponents defend IP mechanisms like plant breeders rights and patents as necessary tools to stimulate-and recoup-investments in these technologies. In Canada, these types of protections have been increasing since the 1970s (see Phillips, 2013). Important to this article, global corporations are not only capable of deploying significant resources to explicitly pursue wider protections, but they also engage in discursive games to increase the acceptance of strong IP mechanisms (Sell, 2009). Corporations frame opposition to IP rights as a defense of intellectual piracy; opponents to this frame argue that the protections themselves are a form of piracy-biopiracy of the genetic resources and traditional knowledges of developing countries (see Drahos \& Tansey, 2008; Shiva \& Holla-Bhar, 1996). On this point, Drahos and Tansey (2008) explain that leverage can be gained by framing arguments along commonly accepted values/principles; these "floating points of leverage" can be deployed by powerful and less powerful actors alike.

Pro-poor narratives which position GM foods and crops as the solution to world hunger are prevalent in agri-biotech discourse, and represent another key example wherein language use in GMO debates is embedded in the power of framing (see Chopra, 2015; Glover, 2009; 2010; Kleinman \& Kloppenburg, 1991). Glover (2010) highlights the ways in which perceptions regarding agricultural biotechnology have been shaped by narratives of how GMOs will help to alleviate global hunger and poverty. Ideological commitments to double food production for a growing population, however, work to marginalize issues like global diet and lifestyle trends (Tomlinson, 2013). According to Tomlinson (2013, p. 81) "the imperative to double global food production by 2050" is now ubiquitous when discussing international food security policy ${ }^{4}$, but the key is whether or not this imperative is used as a normative goal or a projected (and not necessarily desirable) future. If the prediction that we will need to double food production is transformed into a normative imperative, wherein we commit to finding a way to actually double food production to satisfy population growth, we may fail to explore other options to improve access, distribution, and waste, for instance. A reason for this transformation, Tomlinson (2013) suggests, may be that the goal of doubling global food production aligns well with ideological commitments to economic growth, liberalized trade, and technological and scientific problem solving. Glover's (2009) research explains how hidden assumptions that have shaped the propoor narrative of agricultural biotechnology "have involved the radical simplification of the complex agronomic and livelihood contexts into which GM crops have been inserted”. This process of simplification helps to illustrate the connections between power and discourse- the ways in which technological assessments can be translated into political commitments. Sharratt (2001a) contributes to this argument, stating:

Genetic engineering is sold as the solution to world hunger and increasing environmental degradation in an attempt to justify and legitimate genetic engineering as a technological fix for problems

\footnotetext{
${ }^{4}$ The Millennium Development Goals (particularly Goal 1) and the Post-2015 Development Agenda are important sites for this discussion of international food security policy.
} 
that are largely social, political, and economic rather than technical. (p. 8)

A pre-occupation with technological and scientific solutions to global problems may restrict our vision, shadowing more efficacious alternatives such as re-peasantization ${ }^{5}$. Such efforts to influence public perceptions and policy debates regarding agricultural biotechnology involve complex power relations which include discursive battles over the production of "truth".

“Truth”, or more precisely, the power and politics of truth, represents an important site for analysis regarding GMO discourse. In Foucault's (1984) view, in each society there is a general politics or regime of truth, which refers to

the types of discourse which it accepts and makes function as true; the mechanisms and instances which enable one to distinguish true and false statements, the means by which each is sanctioned; the techniques and procedures accorded value in the acquisition of truth; the status of those who are charged with saying what counts as true. (p. 73)

Scientific discourse, including the actors and institutions that produce it, plays a key role in our current truth regime. Wynne's (2001) critique of contemporary GMO policy illustrates this role, particularly "the ways in which science has become the culture of policy rather than its key intellectual resource” (p. 472). Dominant constructions of GMO discourse position scientific knowledge (specifically conventional, reductionist forms of science) as objective and unquestioned, and public discourses as ungrounded and emotionally based. As such, public perceptions are represented as opinions without any intellectual weight, while the scientific knowledge culture remains unreflexive of its own value commitments (Wynne, 2001).

In their analysis of Monsanto's efforts to shape public opinion and political debate over biotechnology, Kleinman and Kloppenburg (1991) outline how "discursive elements with historical resonance" are drawn from in order to create a positive image of biotechnology - two prime examples being technological determinism and scientific expertise (p. 427). According to Kleinman and Kloppenburg (1991), these historically embedded ideas benefit Monsanto's efforts to create "an image of biotechnology as developing inevitably along a particular trajectory, as immanently and universally beneficial, and as a realm appropriately assessed only by experts” (p. 431). These authors illustrate the potential impacts of historically and normatively embedded understandings of what counts as "truth", and how these understandings are deployed. GMO debates include long-standing discursive battles over how to view and understand new technologies; this fight over the "truth" about GMOs deserves further critical attention.

\footnotetext{
${ }^{5}$ Re-peasantization, or the restoration of varying forms of peasant agriculture, has been promoted to counter "the threat presented to world food security by the third crisis and by food empires” (van der Ploeg, 2007, p. 332).
} 


\section{GMO debates in Canada}

The Canadian government's dual role as regulator and promoter of agricultural biotechnology has been criticized for its biased, uncritical approach to GMO regulation (Abergel \& Barrett, 2002; Andrée, 2002; Magnan, 2006). A narrow risk focus and prioritization of technological innovation and economic competitiveness has impacted the extent to which the Canadian state has engaged the public in the development of agri-biotech policies (Abergel \& Barrett, 2002). According to Magnan (2006), not only does Canada's supportive position on biotechnology limit its capacity to respond to public concerns, but we can also expect future public relations efforts to vie for support of these technologies.

Although the approval for growing GM crops in Canada has been continuing since the 1990s (i.e. corn, soybean, canola, and sugar beet), anti-biotech campaigns have also been successful on numerous occasions over this time period. For example, in 1994, opposition from several different Canadian organizations was successful in blocking the use of recombinant bovine growth hormone (rBGH) in Canada $^{6}$ (Sharratt, 2001b). Also, Eaton (2009; 2011; 2013) has thoroughly cataloged a similar coalition that successfully opposed the introduction of GM wheat in Canada in the early 2000s. These “victories", however, are not necessarily a bellwether of more cautious agri-biotech policy in Canada. The instances when GM foods/crops have been successfully opposed in Canada represent specific "wins” in the anti-biotech campaign, but have not materialized into an effective transformation of Canada's use and development of GM technology in general. This article contributes to such scholarly discussions of how anti-biotech campaigns have been successful on specific occasions, but less successful in generating more systemic changes. It examines discursive battles in the Canadian agri-biotech arena and identifies varied instances of power imbalance in order to expose important biases and predispositions with regard to public information on GM foods and crops.

\section{Four dimensions of power}

Exploring the impacts of power relations within debates over agricultural biotechnology requires an understanding of the diversity and complexity of these relations. As a theoretical concept, power has been defined and categorized with considerable depth and breadth (see Dean, 2010; 2012; Digeser, 1992; Haugaard, 2002; 2012; Lukes, 1986). A fusion of many works and ideas affords this study the theoretical strength to thoroughly analyze power relations within agribiotech discourse in Canada. This study approaches power as (1) a capacity that is possessed and deployed, by actors such as corporations for example (see Fuchs, 2007; Clapp \& Fuchs, 2009), and (2) as a constitutive, underlying force that establishes and influences other forms of power

\footnotetext{
${ }^{6}$ For a detailed examination of the rBGH controversy in the U.S., including a discussion of shifting patterns of discourse and the consumption politics of food, see Buttel (2000).
} 
(see Digeser, 1992; Rye, 2014). These two approaches to power are interrelated, and in many ways reinforce one another.

Approaching power as a capacity that is possessed and deployed, Fuchs (2007) and Clapp and Fuchs (2009), describe three forms of power: instrumental, structural, and discursive. Instrumental power involves the direct influence of one actor on another. Clapp and Fuchs (2009) usefully conceptualize instrumental power to examine impacts of agri-food corporations on global food systems, for instance, corporate lobbyists have the capacity to influence policy formation. Dahl's (1957) early conception of this form of power focuses on the capacity actors have to influence actions/events through their own actions. Bachrach and Baratz (1962, p. 948) extend Dahl's power concept to include a second "face" of power which investigates the "mobilization of bias"; actors exert power by "creating or reinforcing social and political values and institutional practices that limit the scope of the political process". This form of power is referred to by Clapp and Fuchs (2009) as structural power, an example being agri-food corporations articulating disincentives such as the consequences of lost jobs or added costs to farmers and consumers if too many restrictions and regulations are placed on the industry. These two categories (or “faces”) of power represent important, more explicit, instances of influence and control.

Lukes (1974; 1986) offers a third dimension of power wherein subjects act voluntarily due to modifications in their own values and beliefs. This understanding of power shares similarities with Castells (2013) work on communication power, as well as Gramsci's (1971) discussions of consensus and common sense; however, the focus here is the application of Lukes’ work to the concept of discursive power (see Fuchs, 2007; Clapp \& Fuchs, 2009). Clapp and Fuchs (2009) describe this form of power as preceding decision-making, involving the framing of issues around certain norms and values. This form of power acknowledges the role of media and other public relations mechanisms in framing political issues. The discursive strategy of framing agri-biotech issues is an essential focus of this study; of particular interest is how the strength of certain frames being deployed are (at least in part) constitutive of widespread, longstanding normative assumptions.

Accounting for the influences of such assumptions, Dean (2010, 2012) and Digeser (1992) outline a fourth dimension of power founded upon the works of Foucault (see 1977, 1980). This fourth dimension is referred to here as constitutive ${ }^{7}$ power. Constitutive power provides a critical divergence from the first three dimensions of power-particularly on the point

\footnotetext{
${ }^{7}$ Digeser (1992) provides a strong explanation of this form of power and refers to it as the fourth face of power, or "power ". In order to align the terminology for this type of power with the more descriptive terms used by Clapp and Fuchs (2009) for the first three forms, I have chosen the term constitutive power, which is consistent with the language (which draws heavily from Foucault) used to describe this form of power (See Foucault, 1977; 1980; Haugaard, 2002). The term constitutive also reflects what Barnett and Duvall (2005) refer to as "social relations of constitution", which involves a like-minded application of the fourth dimension of power. Previous uses of the term 'constitutive power' are inconsistent. While some authors position constitutive power as possessed and deployed by actors, such as the state (see Browning \& Christou, 2010; Neocleous, 1996), others view constitutive power as embedded in socially and historically developed norms and discourses (see Jennings, 2011; Rye, 2014). The present study adopts the latter view.
} 
of agency. Constitutive power is not possessed but rather forms the space for exercising power through the historical development of norms and discourses in which actors participate and interact; it comprises the background conditions that form subjects and enable/disable the capacity for agency (Digeser, 1992). Dean (2010) explains that it is useful to look beyond "the identification of agents of power" and to "attempt to understand the kind of power relations in which such forms of agency appear” (p. 461). In this sense, there is a form of power that exists outside of the actions of agents operating towards their own ends. In this study, power is approached in four dimensions to add to the understanding of pro-biotech and anti-biotech battles for public attention. All four types of power interlace in varying combinations depending on the social context. This application of power offers insights into how distinct and interconnected forms of power can be identified, and how certain topics, opinions, and values toward agricultural biotechnology are enabled or constrained.

An example of constitutive power is the influence of scientific discourse in agri-biotech debates. That is, the dominant discourses of scientific reasoning are suitably conceptualized in this fourth dimension of power in order to examine their influences on decision making, and the production of knowledge in general. Andrée (2005) explains that scientific discourse deploys its own form of influence by placing limitations on what makes sense. It should be asked, as Foucault (2003) has:

What types of knowledge are you trying to disqualify when you say that you are a science? What speaking subject, what discursive subject, what subject of experience and knowledge are you trying to minorize when you begin to say: 'I speak this discourse, I am speaking a scientific discourse, and I am a scientist.’ (p. 10)

Actors without scientific-technical knowledge are limited in their capacity to influence policy, regardless of their level of interest in the policy outcome (Andrée, 2005). In this sense, scientific discourses (as a dominant norm) enable and constrain the capacity for agency - the capacity to possess and exercise certain forms of power. Such views are an essential expansion to the study of power relationships within language use regarding agricultural biotechnology. Certain forms of knowledge are embedded in historical and normative understandings of truth which are mobilized by actors vying to win public support.

Utilizing the above framework, this article outlines how-based on a combination of varying power relations_-some discursive ${ }^{8}$ strategies are more powerful than others. Instrumental and structural power relations (such as the supportive actions of the Canadian state) establish a favourable climate for pro-biotech discourse. Further, discursive strategies such as pro-biotech frames are deployed to influence opinion, and such strategies are advantaged by the

\footnotetext{
${ }^{8}$ To be clear, this article applies a four dimensional power framework to an analysis of discourse. One of the key dimensions of power that is being looked at is discursive power, which involves the use of conversation, text, an so forth (i.e. discourse) to influence/persuade other actors. The other three dimensions of power are utilized in this article to add new insights into what influences the development and deployment of pro- and anti-biotech discourse.
} 
constitutive power of historically embedded normative assumptions. I propose a fuller engagement with the breadth of power relations is necessary to help make room for a more openended inclusion of public opinion, and to help add momentum to anti-biotech campaigns that are focused on incisive and systemic critiques.

\section{Data and methods}

A total of 42 key informational documents were compiled from pro-biotech publicity materials and anti-biotech campaign materials ${ }^{9}$. The unit of analysis was limited to materials directed at the Canadian public by the CBI and CBAN whose mandates are to disseminate promotional and oppositional information about agricultural biotechnology, respectively. Materials published by these two organizations from 2010 to 2015 were selected to provide an up-to-date representation of language use and problem framing within Canadian GMO debates. All materials were collected via relevance sampling; using key words and targeting two specific organizations (the CBI and CBAN) allowed for a systematic isolation of relevant materials (Krippendorff, 2012). Sampling was performed on web search engines (e.g. Google) and the respective websites of the CBI and CBAN. Web materials, including advertisements, pamphlets, flyers, booklets, web pages, and other downloadable documents were compiled. The materials by CBAN were a combination of single-page flyers for campaigns and multi-page booklets with detailed information. Materials from the CBI consisted largely of brief, three to four page documents covering a specific topic (for example, drought), but also included a cookbook and an activity booklet for children. Documents were selected in a way that covered a wide array of material types, all within a similar time-frame and target audience. Audio/video materials were not included. The documents were manually coded, and analyzed in an iterative process utilizing insights from sociological discourse analysis (see Ruiz Ruiz, 2009) and critical discourse analysis (see Jäger, 2001; Fairclough, 2001; 2013).

The methods used in this study involve a combination of textual analysis, contextual analysis, and reflexive interpretation. First, textual analysis involves looking at the wording, metaphors, and other grammatical elements of a text (Jørgensen \& Phillips, 2002). Second, contextual analysis involves outlining the context of the material being analyzed; including considerations of authorship, audience, and dissemination. Third, reflexive interpretation "involves making connections between the discourses analyzed and the social space in which they have emerged” (Ruiz Ruiz, 2009, p. 25). Here, the social, cultural and historical context of a particular discourse is reviewed. This phase takes place throughout textual and contextual analysis. Following Ruiz Ruiz (2009), analysis was “conducted in a constant and bidirectional manner among these three levels” (p. 25). The methods of discourse analysis employed here leave important questions to be answered by future research. More extensive document analyses

\footnotetext{
${ }^{9}$ Further details about these documents are available from the author.
} 
as well as in-depth participant based investigations regarding public engagement with these discourses, including how certain ideas are interpreted in different ways, will add useful developments to this study's findings. Results from the analysis are outlined below.

\section{Results}

\section{Canada's stance: Pro-biotech boon and anti-biotech battle}

It is well established that the Canadian state plays a dual, contradictory role as both regulator and promoter of biotechnology (Magnan, 2006; Prudham \& Morris, 2006). This dual role contributes to the production of discourses by both industry and the Canadian state which appear mutually supportive, including the use of complementary (and sometimes identical) language in descriptions of Canada's approach to regulating agricultural biotechnology. Furthermore, Magnan (2006) explains that "given the state's role in regulating and actively promoting the technology, government-sponsored public consultations have taken on the aura of public relations and have risked foreclosing meaningful opportunities for debate” (p. 25). This stance by the Canadian state works to stifle approaches to more open and transparent policy development.

According to Kneen and Kuyek (2002), successive Canadian governments have supported the biotech industry since 1980. The supportive stance of the Canadian government is depicted in their deployment of instrumental and structural power to advance the development of the agri-biotech sector. Federal policies like the 1983 National Biotechnology Strategy and the 1998 Canadian Biotechnology Strategy are strong representations of instrumental power as they are explicitly designed to foster development and innovation in the sector. These policies helped create a favourable climate for GMOs and established agricultural biotechnology as an economic, technological, and scientific priority in Canada.

An important aspect of the Canadian Biotechnology Strategy was the creation of the Canadian Biotechnology Advisory Committee (CBAC), which Health Canada (2005) describes as "an arms-length committee consisting of multidisciplinary experts and members of the general public”. CBAC's activities regarding the regulation of GM food in Canada offer a clear example of structural power; critics have described the nomination procedures for the members of CBAC as biased against experts critical of biotechnology (Magnan, 2006), and the stakeholder consultations held in 1998 and 2001 as undemocratic, because they were private, by-invitation meetings (Barrett, 2002). As Gerlach, Hamilton, Sullivan, and Walton (2011) describe it:

The format, structure and nature of the process results in participation by direct stakeholders and excludes the population at large. As a result, conclusions and recommendations are predetermined and robust exchange over ethical and social concerns is neatly avoided (p. 117-8). 
The Canadian government effectively mobilized their bias towards the development of a biotechnology sector through CBAC's consultation efforts.

Canada's regulation of agricultural biotechnology has also been criticized for its case-bycase, product-based approach. Each novel agricultural product is assessed and regulated based on its novelty, not on the processes of production (CFIA, 2007). This system regulates several different product development technologies ${ }^{10}$ within the same legislative framework, focusing on the characteristics of each individual product. Instead of viewing GM products as being developed from a distinct process needing unique regulatory mechanisms (e.g. GMO laws), GM products are grouped with other "novel agricultural products" and regulated within a system already set in place (Tait \& Levidow, 1992). One particularly contested aspect of these productbased regulations is the concept of substantial equivalence. The essential idea is that GM crops deemed compositionally similar to crops already approved and on the market, may be exempt from certain safety assessments and other requirements because their risk is deemed comparable to an already approved crop (see Clark, 2004; Prudham \& Morris, 2006) ${ }^{11}$. Substantial equivalence, and other aspects of Canada's GMO regulatory system, such as the efficacy of tests for toxins and allergens (see Clark, 2004) and a purely voluntary labelling standard for GM foods, provide grounds for critiques that this system is weighted in favour of industry development and away from a precautionary logic (see Prudham \& Morris, 2006). This regulatory framework is an important component of the overall positive stance to biotechnology taken by the Canadian state. Of particular interest to this study is how the Canadian state's instrumental and structural power in this area might shore up pro-biotech publicity discourse. Analysis reveals that the Canadian state's supportive stance on agricultural biotechnology, including the establishment of product-focused regulations, acts as a boon to pro-biotech publicity materials and a point of critique in anti-biotech campaign materials.

\section{Canada's positive stance is a boon to pro-biotech discourse}

The Canadian state and the agri-biotech industry provide a mutual boon to one another in their descriptions of the industry and government processes of regulation and scientific assessment. Analysis revealed that the Canadian state's overall supportive stance toward agricultural biotechnology is utilized within pro-biotech publicity discourse; language use by the Canadian Food Inspection Agency (CFIA) also includes phrases that mirror that of the CBI. For instance, while the CBI (n.d.) notes that "Beer, wine, bread and cheese were the original biotech foods" (p. 3), the CFIA (2007) similarly states "Biotechnology has long been used to make everyday

\footnotetext{
${ }^{10}$ In addition to genetic modification, the types of technologies used to develop other PNTs include: chemical mutagenesis of plant seeds, like sunflowers; high pressure processing for egg salads, dips, and spreads; and adding phytosterols to juices and yogurts (Health Canada, 2015).

${ }^{11}$ For further details see CFIA Directive 94-08 (Dir 94-08) Assessment Criteria for Determining Environmental Safety of Plants With Novel Traits (2016), http://www.inspection.gc.ca/plants/plants-with-noveltraits/applicants/directive-94-08/eng/1304475469806/1304475550733
} 
products (e.g. the use of micro-organisms, such as bacteria or fungi, to manufacture cheese, wine, and antibiotics)" (p. 6). These statements showcase mutual efforts by government and industry to historicize and normalize the use of biotechnology applications in food and agriculture.

The CBI's (2011b) four-page factsheet "Understanding Canadian Biotech Regulations" includes several excerpts which illustrate how Canada's positive stance toward biotechnology is integrated into their publicity materials. One of the opening paragraphs reads:

The Canadian plant biotechnology industry is regulated by our federal government. Our stringent regulatory system, with its checks and balances, ensures that all products of biotechnology are safe for people, animals, plants and our environment before they are made available to the consumer. This includes an extensive safety review by both the Canadian Food Inspection Agency (CFIA) and Health Canada. (CBI, 2011b, p. 1)

These statements capture the CBI's efforts to intertwine industry actors with Canada's regulatory system and government organizations. By emphasizing adjectives like "stringent" and "extensive", the CBI points to their overall agreement with, and adherence to, the current Canadian system of agri-biotech regulation. Also, the use of the possessive adjective "our" is a subtle but important textual attribute which couples industry and government actors. By referring to "our current regulatory system" the CBI is able to clearly assert their support for 'stringent' regulations that are designed to ensure the safety of their products. Another excerpt that integrates the actions and commitments of government and industry, states:

Beyond government regulations, the plant science industry develops training and educational materials such as the CropLife Canada Compliance Management for Confined Field Trials Program which has trained over 300 Canadian researchers on how to properly conduct research trials. (CBI, 2011b, p. 4)

Here, the CBI outlines how pro-biotech trade associations like CropLife take part in training and education activities that act as a complement to government regulations. In addition to the coupling of industry and state responsibilities, this document explains how Canada's regulatory system is in line with the international community:

Canada's regulatory guidelines are based on scientific principles and were developed in conjunction with experts in the global scientific community including the United Nation's Food and Agriculture Organization (FAO) and the World Health Organization (WHO). (CBI, 2011b, p.1) 
The CBI references Canada's commitments to scientific principles, experts, and the international community to defend Canada's regulatory system, and by extension, defend the level of assessment their products receive. This quote points to the global scale of agri-biotech discourse, and the role of international organizations. The Food and Agricultural Organization of the United Nations (FAO) has a history of involvement in researching the importance of agricultural biotechnology (Phillips \& Ilcan, 2007), and is shown pushing for expert and scientific knowledges in the governance of agriculture on a global scale (Ilcan \& Phillips, 2003; Phillips \& Ilcan, 2007). Claiming Canada's science-based regulations are consistent with "experts in the global scientific community” offers a wider network of supportive stances to substantiate industry practices. The CBI is defending the agri-biotech industry in Canada by arguing that the FAO and WHO influenced the development of Canadian regulations. In this sense, the CBI is projecting the biotech industry as a positive contribution to agriculture, operating in a system supported by Canadian and international decision makers. Overall, instrumental and structural power relations, such as support for the agri-biotech industry by the Canadian state and international organizations, appear to shore up pro-biotech publicity discourse.

\section{Anti-biotech campaigns react to Canada's regulations and positive stance}

The strong commitment to biotechnology by the Canadian state, including its product-focused regulatory structure, appears to impact anti-biotech campaigns in two ways: (1) anti-biotech discourse includes criticisms of certain government decisions and actions in response to the nonneutral position of the Canadian state, and (2) Canada's product-focused regulatory structure works to, for better or worse, prefigure CBAN's campaign directions to the targeting of specific GM products.

Although it may be unsurprising (if not expected) that CBAN's campaign materials include criticisms of government decisions/regulations, it is useful to include examples of this language use to illustrate how CBAN's positionality toward the Canadian government gets reflected in discourse. Two brochures against the introduction of GM salmon include the following statements:

We call upon the Federal government to stop any current safety assessments of GE fish until the completion of a full, transparent, open and accessible public consultation on the social, ecological, human health, and market implications of introducing GE fish has been completed and its findings have been debated in Parliament. (CBAN, 2011)

In late 2013, Environment Canada announced its decision to allow production of the GM fish and fish eggs in Canada. This is the first government approval for this GM fish anywhere in the world.

(CBAN, 2014b) 
These statements target the Canadian government's avoidance of "open and accessible public consultations", and highlight Canada's supportive (or at least permissive) stance toward GMOs, specifically GM fish. The contrast between CBAN's statements and the CBI's depiction of industry and government as allies illustrates the imbalanced standing of these opposing organizations, and its impact on their associated discursive strategies. The CBI is able to capitalize on the non-neutral position of the Canadian state while CBAN wages criticisms against both.

Of the materials analyzed from CBAN, a consistent theme was to focus on the opposition to specific GM products. Canada's GMO regulations are product-based, meaning that assessment is based on a product's novelty and not the processes of modification (CFIA, 2007). This means that each new GM crop is assessed for health and environmental impacts before it is commercially grown, inevitably leading to protest from those opposing the new GM product. Recent campaigns (2013-2014) have specifically focused on GM alfalfa, apples, fish, and sweet corn, among others.

As mentioned, targeted campaigns have achieved considerable success in Canada; rBGH in 1994 (Sharratt, 2001b), Roundup Ready wheat in 2004 (Eaton, 2009), and GM alfalfa in 2013$14^{12}$. These victories should be considered important successes, especially due to the prominence of these products in Canada ${ }^{13}$. The potential drawback from targeted campaigns is whether the specificity of anti-biotech campaign materials will inadvertently validate the overall biotech system, or at a minimum, do little to oppose it. As Jasanoff (2005) explains, "deeper theoretical perspectives on what is at stake in the politics of biotechnology-more specifically, what is new and debatable about the politics of engineering life - tend to get lost in the noise about the individual application" (p. 185). While anti-biotech campaigns usefully target each GM product that is developed in, and assessed by, Canada's regulatory system, the more general critiques of agricultural biotechnology advanced by CBAN risk being buried within these targeted, productfocused materials.

Campaign discourses vying for an alternative regulatory system and explicit recognition of the potential long term, systemic impacts of GMOs, such as the increased privatization and commodification of plant breeding, are only briefly covered in the focused campaigns against, for example, GM corn. Within their campaign materials opposing Monsanto's "SmartStax" GM corn which "stacks" together multiple traits in a single GM product, CBAN critiques Health Canada for waiving the need for safety assessment (because the product combines only traits that have been previously assessed). CBAN highlights the ways SmartStax technology contributes to Monsanto's increasing control over the seed market; and also advocates for a moratorium on new crop/food approvals and "a comprehensive reform of the entire regulatory system in Canada" (CBAN, 2009; 2010). Here, key positions against the systemic impacts of GMOs and the need

\footnotetext{
${ }^{12} \mathrm{GM}$ alfalfa has recently been released in Eastern Canada, and campaigns continue to efforts to prevent contamination and further release.

${ }^{13}$ For example, spring wheat, which would have been replaced by Roundup Ready wheat, is Canada's largest crop in terms of total production tonnage, reaching an estimated 20 million tonnes of production in 2014, and is the second largest crop in terms of area seeded, at 7 Million hectares (Statistics Canada, 2014).
} 
for a broader alternative regulatory framework are relatively buried within the individualized campaign against GM corn.

Importantly, CBAN has also released broader, more extensive critiques of national and global issues regarding GMOs. A yearlong campaign called “GMO Inquiry 2015” includes six reports totalling 239 pages of research that provides an evaluation of the first 20 years of GM technology (gmoinquiry.ca). The broader, systemic critiques that may get overshadowed in individual campaigns are explored in depth in these reports, including evaluations of the impacts GMOs have on consumers, farmers, and the environment. Future research on the overall reach of these longer, more extensive reports is needed for revealing their potential impact in comparison to the more product-focused campaigns. The next section exposes further nuances within these discursive battles, including how the framing of GMOs intersects with embedded norms and values.

\section{Framing GMOs: Another pro-biotech boon and anti-biotech battle}

Discursive power is about the potency of the frames actors use to couch their preferences, which are deployed as a strategy to influence policy (Sell, 2009). Corporate actors, according to Clapp and Fuchs (2009), often play a role in framing certain problems in public discourse, which can indirectly influence the options being considered to address them. Analysis of frames/framing dates back (at least) to Goffman's (1974) work, and plays an important role here in the examination of pro- and anti-biotech publicity/campaign materials. As Entman (1993) explains, "the frame determines whether most people notice and how they understand and remember a problem, as well as how they evaluate and choose to act upon it" (p. 54). Of concern here is how agricultural biotechnology is being framed in pro-biotech publicity materials, as well as how problems (such as food insecurity) are assigned into categories by associating them with particular norms and values (see Kooiman, 2002 as cited by Clapp \& Fuchs, 2009). Global problems such as world hunger and environmental degradation are defined by pro-biotech actors as problems of efficiency and production capacity, solvable through technological innovation and scientific expertise (see Borlaug, 2004). This framing is understood here as an example of discursive power.

It is also useful to consider the conditions that contribute to the potency of these frames, including the historically and culturally developed norms and values embedded in these frames. Viewed as a form of constitutive power, these conditions set the stage for framing by privileging particular forms of knowledge, and particular means for producing "truth". Normative assumptions developed over time through historical and cultural interactions comprise the background conditions for agency, outlining which actions and ideas are rational, logical, and defensible (see Andrée, 2005; Digeser, 1992; Moore, Kleinman, Hess, \& Frickel, 2011). In this study, technological progressivism and scientism are two powerful forces that enable the capacity/agency to frame certain problems as solvable through agricultural biotechnology. In the sections below, I set forth two arguments: (1) the potency of pro-biotech frames are constituted 
and sustained by long-standing values and norms, and (2) anti-biotech campaigns have the challenge of finding ways to counter these dominant frames.

Pro-biotech frames: Technological progressivism and scientism

According to Entman (1993), framing is about selecting particular aspects of a "perceived reality" and making them stand out in order to promote a particular view of a problem (p. 52). The CBI's publicity materials frame agricultural biotechnology as a solution to global problems, particularly regarding food security and the environment. A factsheet by the CBI (2011d, p. 1) entitled "Protecting Our Planet” states:

Modern plant biotechnology products help our farmers produce a safe, healthy and abundant food supply, while reducing agriculture's environmental footprint. This technology allows farmers to produce more food on the same amount of land, reducing the need to expand land for crop production.

Biotechnology is also positioned as a solution to drought in Africa:

Sharing technology around the world - Canadian biotech company, Performance Plants Inc has signed an agreement to share its drought-fighting seed technology with Africa Harvest Biotech Foundation International (CBI, 2011a, p. 4).

The above quote is from a booklet called Biotech Basics which outlines the importance of growing more food per acre under subheadings like "Feeding a hungry world" and "Doubling food production for the planet by 2030” (CBI, n.d, p. 6-7). Overall, these pro-biotech publicity materials illustrate the CBI's discursive efforts to articulate how agricultural biotechnology can help feed a starving and growing population, all while "helping improve the health of the Earth and the people who call it home” (CBI, 2010).

What makes assertions about feeding a hungry world with GMOs problematic is the political-economic value embedded in making this assertion, and the ways in which this limited approach to solving global poverty and hunger focuses on a small set of technologies instead of the agricultural knowledge of farmers, for example (Chopra, 2015). Furthermore, such narrow approaches downplay the risks and potential disadvantages associated with pursuing these technological solutions (Glover, 2010). Kleinman and Kinchy's (2003) discussion of technological progressivism illustrates the impacts of depending on (bio)technical solutions, and the danger of understanding technological progress as an end instead of a means. Such discourses are deployed to influence public opinion regarding the necessity of agricultural biotechnology, and take advantage of the constitutive power of historically formed normative assumptions about the value and importance of technological progress. 
The assumption that progress is an essential part of modernity dates back to the Enlightenment (Kleinman \& Kinchy, 2003; Kneen, 2013). This is a common theme among the pro-biotech materials analyzed, and has been identified before. In outlining technological determinism as a discursive element in Monsanto’s promotional campaign, Kleinman and Kloppenburg (1991) argue "this view implies that technology has a logic of its own that directs it along a single inevitable trajectory” (p. 432). With regards to CBI's fact sheet "Protecting Our Planet", the coupling of technological improvement with the environment is important because it positions environmental sustainability as achievable through technical means, supporting the single inevitable trajectory of bio-technical environmental solutions. The issue here is the promotion of technological progress, specifically in the area of biotechnology, to combat global social problems like climate change and food insecurity. These complex problems are narrowly defined by technical solutions ${ }^{14}$, marginalizing non-technical solutions that are not tied to political-economic interests.

In addition to themes reflecting technological progressivism, the CBI also actively invokes frames that seek to strengthen and legitimize their position on agricultural biotechnology by aligning it with trusted, authoritative sources. In a recipe book by the CBI (2011e) entitled “Good Ideas are Growing”, nutritionists and registered dietitians are quoted in support of the consumption of canola, corn, legumes, soybeans, and wheat-most of which are available as GMOs. Adherence to expert opinion points to the strategy of downplaying dissenting opinions by maintaining the divide between public perceptions of GM crops, and the allegedly objective opinions of “experts” (Stirling, 2012). Importantly, some of the CBI's most pervasive references to experts and procedures that legitimize agricultural biotechnology had to do with the adherence to scientific principles ${ }^{15}$. Statements wherein science is given implicit importance and credibility include:

Through plant science innovations, including biotechnology, Canadian farmers are ensuring high productivity rates and increased food quality (CBI, 2011c).

Furthermore, the mandate listed on most of the CBI's publicity materials includes the phrase:

The Council for Biotechnology Information is a non-profit association whose mandate is to communicate science-based information about the benefits and safety of agricultural and food biotechnology (see CBI, 2011d, p. 4).

\footnotetext{
${ }^{14}$ Problem solving through technological progressivism can also have unintended consequences- the Green Revolution provides a fitting example, significant production increases were achieved alongside "unintended environmental, social, and institutional consequences" (Pingali, 2012, p. 12302).

${ }^{15}$ CBI's (2010) children's activity booklet "Look closer at biotechnology" was analyzed for numerical indications of word repetition - directed toward children, this booklet offers a brief (2,583 words), clear, and simple discussion of biotechnology. Interestingly, the word "scientist(s)" appeared 25 times, making it the third most common word in the document (discounting grammatically necessary words such as prepositions and articles). The word occurring most frequently was "biotechnology" (64 times), and the second most common was "grow" (26 times).
} 
These statements position science-based information as authoritative, necessary, and unquestioned. Andrée (2005), drawing from Foucault, explains how scientific discourse exhibits a normalizing power in politics, marginalizing actors without the requisite expertise and limiting avenues of resistance. The CBI uses the concept of "science-based information" to validate their position. Implicitly, such statements work to disqualify and "minorize" other forms of knowledge that are not defined as science-based (see Foucault, 2003). By using scientific knowledge as a defence for GM technology, the CBI is essentially placing science-based information above other sources, such as social and ethical considerations. This use of "science" as a defence for agricultural biotechnology is a persistent theme in pro-biotech publicity materials.

To be clear, it is not the discipline of science that needs critiquing here, nor should these arguments be viewed as an opposition to science, and scientific reasoning. Of particular concern here is the use (or misuse) of "science", or more accurately, conventional scientific discourse, for a particular purpose. As Wickson and Wynne (2012) point out, when science is used for policy development in contested areas like GMOs, it can be used to close down policy debate to a limited number of experts instead of providing a range of options to democratically accountable policy makers. This is a key problem regarding the regulation and governance of GMOs, as scientific assessments are an invaluable aspect in decision-making on these technologies, but scientific discourse can also be mobilized to overshadow other forms of knowledge. As Bronson (2014) illustrates, the courtroom dialogue in Schmeiser v. Monsanto clearly showed a privileging of scientific expertise as a more credible source of knowledge.

Of particular interest to this study is what constitutes the "internal regime of power" of scientific statements; what forces (social, economic, cultural, etc.) are behind the production of "truth" (see Foucault, 1984). More to the point, Stirling (2012) explains that "if one believes that science discovers facts and that facts determine technology, then there is little latitude for meaningful social engagement on the direction of technology change” (p. 3). As such, strategies that privilege scientific knowledge for the purpose of marginalizing other perspectives need to be identified. Notions of ‘scientific expertise' and ‘science-based information' are understood here as the products of constitutive power; these embedded normative assumptions produce accepted "truths" that actors like the CBI can draw on to shore up their discursive power.

The notion of "scientism" is useful here for capturing this strategy of mobilizing scientific discourse; according to Kleinman and Kinchy (2003) "scientism is the notion that values should not be allowed to mix with facts, and, further, should not be considered in decisions about science and technology” (p. 379). Within the materials analyzed for this article, terms such as "scientific" and "science-based" are used by different actors to validate arguments, and depend on pre-conceived understandings of what makes information reliable. Here, the CBI deploys discursive power by calling upon the defense of "science"; these messages are fortified by the constitutive power of scientific discourse, which occupies a privileged position in the production of "truth" and makes claims regarding the science-based regulation of GMOs more 
salient. As Irwin and Wynne (1996) explain, “to accept science as a key resource in public issues is radically different from accepting its automatic authority in framing what the issues are” (p. 89). This use of science, or more accurately the normative weight of science, results in the displacement and/or demotion of other forms of knowledge in contexts such as policy making.

\section{Anti-biotech's response to established normative assumptions}

Pro-biotech materials from the CBI utilize frames about helping the environment and a hungry planet, which are bolstered by a history of technological progressivism and scientism. The discursive response of anti-biotech campaigns is, by necessity, an uphill battle wherein organizations like CBAN find themselves navigating (and at times fighting against) preestablished normative assumptions about what the food and agricultural system should look like. That is, CBAN is (unsurprisingly) not in opposition to environmental and humanitarian efforts or scientific and technological developments. Therefore, creating an anti-biotech campaign response to pro-biotech claims about feeding the world and saving the environment poses a unique challenge: with decidedly less resources than the CBI, CBAN's role includes dispelling these claims that are upheld by longstanding norms regarding technology and science.

Though not a Canadian crop, CBAN's extensive critique of GM “Golden Rice” provides a strong and useful illustration of its opposition to pro-biotech frames that promote the humanitarian value of GMOs. In a 2014 factsheet, CBAN effectively challenges aspects of biotechnology linked to humanitarianism in regards to Golden Rice, the GM rice with added beta-carotene ${ }^{16}$ to address vitamin A deficiency (CBAN, 2014a). CBAN exposes several drawbacks to the long awaited promises of Golden Rice, including financial costs, inadequate testing, environmental risks, as well as the general notion that Golden Rice is prescriptive to an isolated issue within the larger problems of hunger and malnutrition (CBAN, 2014a). This eight page factsheet represents the complex critical research and campaign efforts needed for building an opposition to frames that are latched on to issues like global hunger.

Another example wherein CBAN unravels the pro-biotech claims to humanitarianism is the sixth report in GMO Inquiry 2015, “Do we need GM crops to feed the world?” (CBAN, 2015a). In this 24-page report, the "feed the world" rhetoric is criticized, explaining that GM crops fail to account for a range of social, economic, and environmental issues related to global hunger (CBAN, 2015a). CBAN appears well equipped to challenge pro-biotech frames that offer simple solutions to complex global social and environmental problems, though deconstructing and refuting the minutia of these claims also appears to be a fairly elaborate and research intensive task.

CBAN's campaign materials also include arguments that push back against the normative assumptions of conventional scientific reasoning and the inevitability of technological progress. Importantly, CBAN does not formulate arguments that are outright against scientific knowledge and technological development. Whether or not this reflects the prevailing influence of scientism

\footnotetext{
${ }^{16}$ The rice is engineered to produce beta-carotene which is then converted to vitamin A in the body.
} 
and technological progressivism, it is useful to point out that a more appropriate assessment of CBAN's position is one that endorses a complexity approach to science and a precautionary approach to technology.

CBAN problematizes the narrow approach to science utilized by pro-biotech industry and government actors. For example, in a flyer opposing GM salmon, CBAN (2011) writes:

The FDA released two documents that summarize the data presented by AquaBounty as well as the FDA's own analysis of the company's science. But the data was widely criticized as woefully inadequate, shoddy science. In public meetings, the FDA's own committee members voiced serious concerns about the risks and the quality of the data.

This quote targets the quality and adequacy of AquaBounty's scientific research. Additionally, CBAN (2015b) critiques Canada's regulations for not considering social and economic impacts, stating

GM foods and crops are regulated based on a very narrow set of considerations. The government limits risk assessment to (some) safety questions and does not consider 'non-scientific' concerns such as economic impacts. (p. 2)

CBAN's (2015b) critique of Canada's regulatory focus also includes a statement on treating technological development as inevitable:

In Canada, the question of the social worth of individual GMOs is not determined through regulation but is left for the market to decide. The federal government has already decided that the new technology and the growth of the biotechnology sector serve the public good. (p. 4)

The above three quotes offer an illustration of CBAN's treatment of science and technology. Overall, this treatment reflects CBAN's mission, which is to promote "food sovereignty and democratic decision-making on science and technology issues”. Though not explicit in their materials, these positions can also be viewed as depicting the anti-biotech campaign's alignment with complexity science.

As the remaining uncertainties regarding GMOs work to erode levels of trust and credibility in reductionist approaches to scientific assessment, complexity science is increasingly being looked to for alternatives. Complex problems with unsolvable uncertainties necessitate discussions of choice, priorities, and interests (Gibson, 2005); this means moving from reductionist scientific approaches, to more complexity oriented approaches (see Stirling, 2010). Wickson and Wynne (2012) point to this phenomenon in the European context, wherein scientific risk assessments have faced considerable criticism for their failure to recognize the 
ways in which values are embedded and intertwined in the conducting and interpreting of these assessments. Though such criticisms are not absent in Canada (see Clark, 2004), the policy and regulatory debates and changes in Europe are useful indications for what a Canadian system based on precaution and complexity science may look like. This is due, in part, to the strong antiGM sentiments commonly attached to European consumers and institutions (see Moses \& Fischer, 2013). What is needed, as Stirling (2012) suggests, is "greater public engagement [that] offers an opportunity to be more rigorous about the uncertainties in bioscience innovation and more accountable about the exercise of power" (p. 1). Future anti-biotech campaigns may benefit from the continued pursuit of this wider lens, elaborating on critiques regarding the necessity of progress and finding new ways of highlighting the value of diverse, non-scientific perspectives (see Stirling, 2009).

\section{Conclusion}

This study examines the state of agri-biotech discourse in Canada, including how the industry frames GMOs, the potency of these frames, and the responses of anti-biotech groups. "GMO doublespeak" is about powerful actors' strategic use of language in efforts to influence the meaning and reception of certain ideas, words, and discourses - this term is used in this article to draw attention to the political language games that play an important role in debates over agricultural biotechnology. Analysis of publicity and campaign materials reveals important power relations regarding efforts to inform public opinion on the topic of GMOs, including the influence of embedded normative assumptions.

First, I have argued that the Canadian state's overall positive position toward agricultural biotechnology provides added leverage to pro-biotech publicity materials, while Canada's regulatory laws and favourable stance on GMOs predisposes anti-biotech campaigns to engaging in certain forms of critique. This illustrates the interplay between GMO discourse and the instrumental and structural power of the Canadian state. Second, I argue dominant pro-biotech frames receive a boost in potency because they are attached to popular values and constructed within historical, cultural, and normative understandings of "truth" production which increase their resonance-whereas anti-biotech campaigns dedicate resources to deconstructing and dismantling these frames. This section demonstrates how discursive strategies are supported by the underlying effects of constitutive power; dominant normative discourses act as a force beyond the direct capacity/agency of the CBI and CBAN. Put briefly, the CBI's discourse fits more readily within the status quo which may improve its overall resonance with the general public. Incorporating constitutive power into this analysis helped to highlight aspects of agribiotech power relations that are not currently emphasized in the literature.

How might the anti-biotech campaigns of organizations like CBAN best proceed over the next two decades? Is it potentially more effective to withdraw from larger, more incisive and systemic critiques of the current agri-biotech system of production, assessment, and regulation? 
Protests against GM wheat, for example, owe their success (in part) to the coalition of key supporters that adopted less radical perspectives regarding economic concerns and potential market impacts (Magnan, 2007). Such perspectives can be viewed as less radical because they pose little to no challenge to the overarching system of agricultural production-advocates for more radical change typically identify fundamental, far-reaching concerns of a systemic nature. Campaigns against rBGH had a similar experience with support from the Dairy Farmers of Canada (Andrée, 2011). Thus, the potential value of a more inclusive, and less radical, approach should not be discounted. At the same time, caution can be gleaned from Dauvergne and LeBaron (2014) who asked: “where are the radicals?” in their book on the corporatization of activism, which also states:

Rarely now do "career” activists call for a new international economic order, or a world government, or an end to multinational corporations. Only a select few on the fringes, in the words of Greenpeace cofounder Bob Hunter, still struggle to "mindbomb" the world to form a new "global consciousness".

Working within, rather than against, dominant discourses may prove successful, or it may foster a climate of not-so-radical activism. While GMO protests have been successful in Canada on numerous occasions, such as the resistance to rBGH in 1994 and GM wheat in the early 2000s, it may be important for future research to investigate the reasons for why a wider shift away from agricultural biotechnology still seems like a distant goal. The broader, more systemic critiques found in materials like GMO Inquiry 2015 may represent a critical step towards counterdiscourses that stimulate a new direction for Canadian agriculture and agri-food policy.

A fuller engagement with the many forms of power relations-particularly regarding dominant norms and discourses — is needed to help make room for a more open-ended inclusion of public perspectives around topics of scientific and technological development. In Kleinman and Kloppenburg's (1991) view, “critics are fighting against a deeply established set of meanings"; we need to broaden the debate beyond technical discussions among experts, towards a "consideration of equity in the social distribution of benefits from new biotechnology products” (p. 445). There is a need to push towards a more open approach to evaluating these technologies, one that adopts a plural understanding of progress in order to consider a wide range of alternatives (see O’Brien, 2000; Stirling, 2009; 2012). Future research projects - and future campaigns - have the difficult task of converting deconstructed dominant norms and complexity approaches to science into digestible public discourse that can be widely disseminated and widely understood.

Acknowledgements: I would like to thank the reviewers who provided many useful comments and suggestions. And, I would also like to thank my PhD thesis committee: Jennifer Clapp, Bob Gibson, Suzan Ilcan, Andrea Collins, and André Magnan, for their comments and direction on previous drafts. Any arguments in or shortfalls of this article remain my responsibility. 


\section{References}

Abergel, E., \& Barrett, K. (2002). Putting the cart before the horse: A review of biotechnology policy in Canada. Journal of Canadian Studies, 37 (3), 135-161.

Andrée, P. (2002). The biopolitics of genetically modified organisms in Canada. Journal of Canadian Studies, 37(3), 162-191.

Andrée, P. (2005). The Cartagena Protocol on biosafety and shifts in the discourse of precaution. Global Environmental Politics, 5(4), 25-46.

Andrée, P. (2011). Civil society and the political economy of GMO failures in Canada: A neo-Gramscian analysis. Environmental Politics, 20(2): 173-191.

Bachrach, P. \& Baratz, M. S. (1962). Two faces of power. The American Political Science Review, 56(4): 947-952.

Barnett, M., \& Duvall, R. (Eds.). (2004). Power in global governance (Vol. 98). Cambridge University Press.

Barrett, K. (2002). Food fights: Canadian regulators are under pressure to face the uncertainties of genetically modified food. Alternatives Journal, 28 (1): 28-33.

Borlaug, N. E. (2004). Feeding a world of 10 billion people: our 21st century challenge. Perspectives in World Food and Agriculture 2004, 31-56.

Bronson, K. (2014). Reflecting on the science in science communication. Canadian journal of Communication, 39(4).

Browning, C. S., \& Christou, G. (2010). The constitutive power of outsiders: The European neighbourhood policy and the eastern dimension. Political Geography, 29(2), 109-118.

Buttel, F. H. (2000). The recombinant BGH controversy in the United States: Toward a new consumption politics of food? Agriculture and Human Values, 17 (1), 5-20.

Canadian Biotechnology Action Network (CBAN). (2009). Why “SmartStax" is dumb. Available from http://www.cban.ca/Resources/Topics/GE-Crops-and-Foods-On-theMarket/Corn/Why-SmartStax-is-Dumb 
Canadian Biotechnology Action Network (CBAN). (2010). Info and action flyer on SmartStax. Available from http://www.cban.ca/Resources/Topics/GE-Crops-and-FoodsOn-the-Market/Corn/Info-and-Action-Flyer-on-SmartStax

Canadian Biotechnology Action Network (CBAN). (2011). Stop GM fish flyer. Available from http://www.cban.ca/Resources/Topics/GE-Fish/Stop-GM-Fish-Flyer

Canadian Biotechnology Action Network (CBAN). (2014a). "Golden Rice”: GM vitamin A rice. CBAN Factsheet. Available from http://www.cban.ca/Resources/Topics/GE-Cropsand-Foods-Not-on-the-Market/Rice/Golden-Rice-GM-Vitamin-A-Rice

Canadian Biotechnology Action Network (CBAN). (2014b). GM fish info flyer. http://www.cban.ca/Resources/Topics/GE-Fish/GM-Fish-Info-Flyer

Canadian Biotechnology Action Network (CBAN). (2015a). Do we need GM crops to feed the world? GMO Inquiry 2015

Canadian Biotechnology Action Network (CBAN). (2015b). Are GM crops and foods well regulated? GMO Inquiry 2015

Canadian Food Inspection Agency (CFIA). (2007). Regulation of agricultural biotechnology in Canada: A post-secondary educator's resource. Her Majesty the Queen in Right of Canada.

Castells, M. (2013). Communication power. OUP Oxford.

Chopra, T. (2015). Persistent narratives, persistent failures: Why GM crops do not—and will not- “feed the world". Canadian Food Studies / La Revue Canadienne Des éTudes Sur L'alimentation, 2(2), 209-216.

Clapp, J. \& Fuchs, D. (2009). Agrifood corporations, global governance, and sustainability: A framework for analysis. In: J. Clapp and D. Fuchs, eds. Corporate power in global agrifood governance. Cambridge, Massachusetts: MIT Press, 1-25.

Clark, E. A. (2004). Regulation of GM crops in Canada: Science-based or ....? Retrieved from www.plant.uoguelph.ca/research/homepages/eclark/pdf/science.pdf

Council for Biotechnology Information (CBI). (n.d.). Biotech Basics. On file with author. 
Council for Biotechnology Information (CBI). (2010). Look closer at biotechnology. On file with author.

Council for Biotechnology Information (CBI). (2011a). Addressing the challenges of drought. Fact Sheets. On file with author.

Council for Biotechnology Information (CBI). (2011b). Understanding Canadian Biotech Regulations. Fact Sheets. On file with author.

Council for Biotechnology Information (CBI). (2011c). Food for Your Good Health. Fact Sheets. On file with author.

Council for Biotechnology Information (CBI). (2011d). Protecting our plant. Fact Sheets. On file with author.

Council for Biotechnology Information (CBI). (2011e). Good ideas are growing: Healthy recipes. On file with author.

Council for Biotechnology Information (CBI). (2011f). Frequently Asked Questions. On file with author.

Council for Biotechnology Information (CBI). (2011g). About the Council for Biotechnology Information.

Dahl, R., (1957). The concept of power. Behavioural Science, 2 (3): 201-215.

Dauvergne, P., \& LeBaron, G. (2014). Protest Inc.: The corporatization of activism. John Wiley \& Sons.

Dean, M. (2010). Power at the heart of the present: Exception, risk and sovereignty. European Journal of Cultural Studies, 201013 (4): 459-476.

Dean, M. (2012). The signature of power. Journal of Political Power, 5 (1): 101-117.

Digeser, P. (1992). The fourth face of power. The Journal of Politics, 54(4): 977-1007.

Domingo, J. L., \& Bordonaba, J. G. (2011). A literature review on the safety assessment of genetically modified plants. Environment International, 37(4), 734-742. 
Drahos, P. \& Tansey, G. (2008). Postcards from international negotiations. In G. Tansey \& T. Rajotte (Eds.), The Future Control of Food: A Guide to International Negotiations and Rules on Intellectual Property, Biodiversity and Food Security. Routledge.

Eaton, E. (2009). Getting behind the grain: The politics of genetic modification on the Canadian prairies. Antipode, 41(2): 256-281.

Eaton, E. (2011). Let the market decide? Canadian farmers fight the logic of market choice in GM wheat. ACME: An International E-Journal for Critical Geographies, 10 (1):107-131.

Eaton, E. (2013). Growing Resistance: Canadian Farmers and the Politics of Genetically Modified Wheat. University of Manitoba Press.

Entman, R. M. (1993). Framing: Toward clarification of a fractured paradigm. Journal of communication, 43(4), 51-58.

Fairclough, N. (2001). Critical discourse analysis as a method in social scientific research. In R. Wodak and M. Meyer, eds. Methods of critical discourse analysis. Thousand Oaks, California: SAGE Publications Ltd., 121-138.

Fairclough, N. (2013). Critical Discourse Analysis: The Critical Study of Language. Routledge.

Foucault, M. (1977). Discipline and Punish: The Birth of the Prison. Trans. Alan Sheridan. New York: Random House.

Foucault, M. (1980). Power/knowledge: Selected interviews and other writings 1972-1977. Ed. Colin Gordon, trans. Leo Marshall, John Merpham, and Kate Soper. New York: Pantheon.

Foucault, M. (1984). Truth and Power. In P. Rabinow (Ed.), The Foucault Reader. New York: Pantheon Books, 51-75.

Foucault, M. (2003). Society must be defended: Lectures at the Collège de France, 1975-76, Edited by M. Bertani and A. Fontana, General Editors: F. Ewald and A. Fontana, English Series Editor: A.I. Davidson, trans. David Macey. New York: Picador.

Fuchs, D. A. (2007). Business power in global governance. Boulder, CO: Lynne Rienner.

Gerlach, N., Hamilton, S.N., Sullivan, R. \& Walton, P.L., (2011). Becoming biosubjects: Bodies, systems, technologies. University of Toronto Press. 
Gibson, R. B. (2005). We just don't know: Lessons about complexity and uncertainty in Canadian environmental politics. In R. Paehlke and D. Torgerson (Eds.), Managing leviathan: Environmental politics and the administrative state, second edition (pp. 145170). Peterborough: Broadview Press.

Glover, D. (2009). Undying promise: Agricultural biotechnology's pro-poor narrative, ten years on. STEPS Working Paper 15, Brighton: STEPS Centre.

Glover, D. (2010). Exploring the resilience of Bt cotton's 'Pro-Poor Success Story’. Development and Change, 41(6), 955-981.

Goffman, E. (1974). Framing analysis. An essay on the organization of experience. New York: Harper \& Row.

Gramsci, A. (1971). Selections from the Prison Notebooks of Antonio Gramsci: Ed. and Transl. by Quintin Hoare and Geoffrey Nowell Smith. G. Nowell-Smith, \& Q. Hoare (Eds.). International Publishers.

Haugaard, M. (Ed.), 2002. Power: A reader. Manchester University Press.

Haugaard, M. (2012). Rethinking the four dimensions of power: Domination and empowerment. Journal of Political Power, 5(1), 33-54.

Health Canada. (2005). Canada’s Biotechnology Strategy. Available from http://www.hcsc.gc.ca/sr-sr/tech/biotech/role/strateg-eng.php

Health Canada. (2015). Approved Products: Novel Food Decisions. Available from http://www.hc-sc.gc.ca/fn-an/gmf-agm/appro/index-eng.php

Hilbeck, A., Binimelis, R., Defarge, N., Steinbrecher, R., Székács, A., Wickson, F., ... Novotny, E. (2015). No scientific consensus on GMO safety. Environmental Sciences Europe, 27(1), 1.

Howlett, M. \& Migone, A. R. (2010). The Canadian biotechnology regulatory regime: The role of participation. Technology in Society, 32: 280-287.

Ilcan, S., \& Phillips, L. (2003). Making food count: expert knowledge and global technologies of government. Canadian Review of Sociology, 40(4), 441-461.

Irwin, A., \& Wynne, B. (2003). Misunderstanding science?: The public reconstruction of science and technology. Cambridge University Press. 
Jäger, S. (2001). Discourse and knowledge: Theoretical and methodological aspects of a critical discourse and dispositive analysis. Methods of critical discourse analysis, 32-62.

Jasanoff, S. (2005). "Let them eat cake”: GM foods and the democratic imagination. In M. Leach, I. Scoones, and B. Wynne (Eds.), Science and Citizens. London, 183-198.

Jennings, R. C. (2011). Sovereignty and political modernity: A genealogy of Agamben’s critique of sovereignty. Anthropological Theory, 11(1), 23-61.

Jørgensen, M. W., \& Phillips, L. J. (2002). Discourse analysis as theory and method. Sage.

Kleinman, D. L., \& Kinchy, A. J. (2003). Why ban bovine growth hormone? Science, social welfare, and the divergent biotech policy landscapes in Europe and the United States. Science as Culture, 12 (3), 375-414.

Kleinman, D. L., \& Kloppenburg Jr, J. (1991). Aiming for the discursive high ground: Monsanto and the biotechnology controversy. In Sociological Forum (Vol. 6, No. 3, pp. 427-447). Kluwer Academic Publishers-Plenum Publishers.

Kneen, B. (2013). Disconnecting the dots: Boundaries and rights. Agrarian Studies Colloquium, Yale University, Sept.13, 2013.

Kneen, B. \& Kuyek, D. (2002). Who is behind biotechnology policy in Canada? Canadian Centre for Policy Alternatives - SK, Volume 1, Issue 2.

Kondoh, K., \& Jussaume, R. A. (2006). Contextualizing farmers' attitudes towards genetically modified crops. Agriculture and Human Values, 23(3), 341-352.

Krippendorff, K. (2012). Content analysis: An introduction to its methodology. Thousand Oaks, California: SAGE Publications Ltd.

Lukes, S. (1974). Power: A radical view (Vol. 1). Macmillan: London.

Lukes, S. (1986). Introduction. In: S. Lukes, ed. Power. Oxford, UK: Basil Blackwell Ltd, 1-18.

Magnan, A. (2006). Refeudalizing the public sphere: "Manipulated publicity” in the Canadian debate on GM foods. The Canadian Journal of Sociology, 31(1), 25-53.

Magnan, A. (2007). Strange bedfellows: Contentious coalitions and the politics of GM wheat. Canadian Review of Sociology/Revue canadienne de sociologie, 44(3), 289-317. 
Moore, K., Kleinman, D. L., Hess, D., \& Frickel, S. (2011). Science and neoliberal globalization: a political sociological approach. Theory and Society, 40(5), 505-532.

Moses, V., \& Fischer, S. (2013). Consumer Choice. In Ludlow, K., Smyth, S. J., \& FalckZepeda, J. (Eds.), Socio-Economic Considerations in Biotechnology Regulation (pp. 6779). Springer: New York.

National Academies of Sciences, Engineering, and Medicine. (2016). Genetically Engineered Crops: Experiences and Prospects. Washington, DC: The National Academies Press.

Neocleous, M. (1996). Administering civil society: Towards a theory of state power. Springer.

O’Brien, M. (2000). Making better environmental decisions: An alternative to risk assessment. MIT Press.

Phillips, C. (2013). Saving more than seeds: Practices and politics of seed saving. Burlington, VT: Ashgate.

Phillips, L., \& Ilcan, S. (2007). Responsible Expertise Governing the Uncertain Subjects of Biotechnology. Critique of anthropology, 27(1), 103-126.

Pingali, P. L. (2012). Green Revolution: Impacts, limits, and the path ahead. PNAS, 109(31): 12302-12308.

Prudham, S., \& Morris, A. (2006). Making the market "safe” for GM foods: The case of the Canadian Biotechnology Advisory Committee. Studies in Political Economy, 78(1), 145- 175.

Rye, D. (2014). Political Parties and the Concept of Power: A Theoretical Famework. Springer.

Ruiz Ruiz, J. (2009). Sociological discourse analysis: Methods and logic. Forum Qualitative Sozialforschung/Forum: Qualitative Social Research, 10 (2).

Sell, S. (2009). Corporations, seeds, and intellectual property rights governance. In J. Clapp and D. Fuchs (Eds.), Corporate power in global agrifood governance (pp. 187-223). Cambridge, Massachusetts: MIT Press.

Sharratt, L. (2001a). Deconstructing a science-based regulation: Towards rendering the risks of genetic engineering visible. Thesis (MA). Carleton University. 
Sharratt, L. (2001b). No to bovine growth hormone: A story of resistance from Canada. In B. Tokar (Ed.) Redesigning life? The worldwide challenge to genetic engineering. London: Zed Books.

Shiva, V., \& Holla-Bhar, R. (1996). Piracy by patent: the case of the Neem tree. The Case Against the Global Economy: And for a Turn Toward the Local. Sierra Club: San Francisco.

Statistics Canada. (2014). Estimated areas, yield, production and average farm price of principal field crops, in metric units. Retreived from www5.statcan.gc.ca/cansim/a26

Stirling, A. (2009). Direction, Distribution and Diversity! Pluralising Progress in Innovation, Sustainability and Development. STEPS Working Paper 32, Brighton: STEPS Centre.

Stirling, A. (2010). Keep it complex. Nature, 468(7327), pp.1029-1031.

Stirling, A. (2012). Opening up the politics of knowledge and power in bioscience. PLoS Biol 10(1): e1001233.

Tait, J., and Levidow, L. (1992). Proactive and reactive approaches to risk regulation: the case of biotechnology. Futures, 24 (3), 219-231.

Tomlinson, I. (2013). Doubling food production to feed the 9 billion: A critical perspective on a key discourse of food security in the UK. Journal of Rural Studies, 29, 81-90.

van der Ploeg, J. D. (2007). The third agrarian crisis and the re-emergence of processes of repeasantization. Rivista di economia Agraria, 62(3), 325-332.

Wickson, F., \& Wynne, B. (2012). Ethics of science for policy in the environmental governance of biotechnology: MON810 maize in Europe. Ethics, Policy \& Environment, 15(3), 321-340.

Wynne, B. (2001). Creating public alienation: Expert cultures of risk and ethics on GMOs. Science as Culture, 10(4), 445-481. 